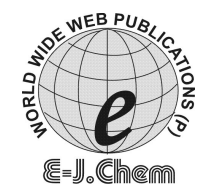

http://www.e-journals.net

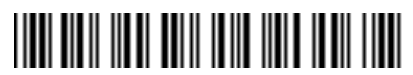

ISSN: 0973-4945; CODEN ECJHAO

E-Journal of Chemistry

Vol. 4, No. 4, pp. 467-473, October 2007

\title{
A Simple Spectrophotometric Determination of Phosphate in Sugarcane Juices, Water and Detergent Samples
}

\author{
MAHADEVAIAH, M. S. YOGENDRA KUMAR, \\ MANSOUR S. ABDUL GALIL, M. S. SURESHA, \\ M. A. SATHISH and G. NAGENDRAPPA* \\ Department of Chemistry, \\ University of Mysore, Manasagangotri, Mysore 570006, India. \\ gnagendrappa@yahoo.co.in
}

Received 13 January 2007; Accepted 5 March 2007

\begin{abstract}
A simple spectrophotometric method is developed for the determination of phosphate in sugar cane juice, water and detergent samples. The method is based on the formation of phosphomolybdate with added molybdate followed by its reduction with sodium sulphide in aqueous sulfuric acid medium. The system obeys Lambert-Beer's law at $715 \mathrm{~nm}$ in the concentration range 0.3-12.24 ppm. Molar absorptivity, correlation coefficient and Sandell's sensitivity values were found to be $6.1 \times 10^{3} \mathrm{~mol}^{-1}$ $\mathrm{cm}^{-1} 0.999$ and $0.0156 \mu \mathrm{g} \mathrm{cm}^{-2}$ respectively. The results obtained were reproducible with acceptable standard deviation $3.7 \%$ and relative error $3.4 \%$. For a comparison of the method phosphate present in various samples were also determined separately following an official method. The results of the developed method compare well with those of the official method.
\end{abstract}

Keywords: Phosphate, water, detergents, and spectrophotometry.

\section{Introduction}

Phosphorus is the eleventh most abundant element on the surface of the earth and is most commonly found as phosphate. It plays an important role in biochemical processes and is a key factor in the eutrophication of surface water ${ }^{1}$ Increased phosphate concentrations are linked with increasing rates of plant growth ${ }^{2}$. The analytical chemistry of phosphorus is very important in many fields, for example, medical and clinical science, agriculture, metallurgy and environmental science ${ }^{3}$. Moreover, in recent years large quantities of phosphate have been used in beverages ${ }^{4}$, detergents ${ }^{5}$, fertilizers ${ }^{6}$ and also in sugar industries ${ }^{7-9}$. 
The literature ${ }^{7-9}$ gives the importance of phosphate during the sugarcane juice clarification leading to cane sugar manufacture. In this context, the chemical action of phosphate during clarification of sugarcane juice assumes significant role particularly when the juice is deficient in natural phosphate content in the range of 300-350 ppm as $\mathrm{P}_{2} \mathrm{O}_{5}$ which is essential for good clarification. In case of less phosphate content in sugarcane juice, soluble phosphate addition is the only alternative to achieve the target value by adding orthophosphoric acid, single super phosphate or triple super phosphate. Therefore, it becomes very important to determine the amount of phosphate in sugarcane juice. As a consequence, various phosphate determination procedures have been reported ${ }^{10-22}$ which include for example, titrometry $^{10}$, complexogravimetry ${ }^{11}$, colorimetry ${ }^{12,13}$, atomic absorption spectroscopy, ${ }^{14}$ flow injection analysis ${ }^{15}$, HPLC $^{16}$ and spectrophotometry methods ${ }^{17-22}$. Among such methods spectrophotometry involving molybdovanadate ${ }^{23}$ and ammonium molybdate ${ }^{16}$ are most commonly used ${ }^{16}$. In ammonium molybdate spectrophotometric method, different reductants have been employed such as tin(II) chloride ${ }^{23,25}$. ascorbic acid $^{26}$ and 1-amino-2naphthol-4-sulfonic acid $^{27}$, Some of these methods also involve complicated and expensive equipments ${ }^{16}$ and need extraction procedure ${ }^{20,23}$ and such techniques are usually not available in common laboratories. Though there are large number of methods ${ }^{10-22}$ available for the determination of phosphate but such methods used in sugar cane juice for phosphate determination are unread, instead only a few methods ${ }^{8,9,23,25}$ have been used. Therefore, it becomes very important ${ }^{7-8}$ to determine the phosphate in sugar cane juice ${ }^{7}$ and sodium sulphide is found to be a very effective reducing agent ${ }^{28}$ but not commonly used for phosphate determination. ${ }^{28}$ Considering the importance of phosphate and its determination in sugar cane juice an attempt is made here to develop the simple spectrophotometric method which is based on the formation of phosphomolybdate with added molybdate ${ }^{16,24}$ followed by its reduction with sodium sulphide ${ }^{28}$ in aqueous acidic medium.

\section{Experimental}

Elico spectrophotometer model SL 171 (Hyderabad, India) with $1 \mathrm{~cm}$ matched quartz cells, Sartorius digital balance readable $0.0001 \mathrm{~g}$ were used.

\section{Reagents}

All the chemical reagents used were of analytical grade and the water used was distilled water. Weighed amount of ammonium molybdate, $1.7081 \mathrm{~g}$ was dissolved in about $150 \mathrm{~mL}$ of warm water ${ }^{27}$; slightly milky solution obtained was cooled to room temperature. It was then transferred into a $250 \mathrm{~mL}$ volumetric flask and diluted to the mark with water.

$0.05 \mathrm{~g}$ of sodium sulphide was transferred into a clean $100 \mathrm{~mL}$ beaker. It was dissolved in about $50 \mathrm{~mL}$ of water and then the solution was transferred into a $100 \mathrm{~mL}$ volumetric flask. The beaker was washed 3-4 times with water and washings were also transferred into the flask and the solution was diluted to the mark with water. The solution was standardized iodometrically ${ }^{28}$ before use.

$0.1145 \mathrm{~g}$ of disodium hydrogen phosphate was transferred into a $150 \mathrm{~mL}$ beaker $^{29}$. It was dissolved in water, then; the solution was transferred into a $250 \mathrm{~mL}$ volumetric flask and diluted to mark with water. The working solutions were prepared by diluting $5 \mathrm{~mL}$ of this solution to $50 \mathrm{~mL}$ with water.

Sulfuric acid $(0.25 \mathrm{~N})$ was prepared by diluting the concentrated sulfuric acid $(\approx 36 \mathrm{~N})$ with water. 


\section{Recommended procedure}

A series of $10 \mathrm{~mL}$ volumetric flasks were arranged. To each flask $0.5 \mathrm{~mL}$ of $0.387 \mathrm{M}$ ammonium molybdate, $3 \mathrm{~mL}$ of $0.25 \mathrm{~N}$ sulfuric acid and aliquots of disodium hydrogen phosphate corresponding to $0.3-12.24 \mathrm{ppm}(0.1, .2,0.3,0.5,1.0,1.5,2.0,2.5,3.0,3.5$, and $4.0 \mathrm{~mL}$ ) were added. Finally, to each flask, $1 \mathrm{~mL}$ of $2.0833 \times 10^{-3} \mathrm{M}$ sodium sulphide solution was added. Then, each solution was let at room temperature for about $20 \mathrm{~min}$. The absorbances of solutions were measured at $715 \mathrm{~nm}$ against water.

\section{Sugarcane juice sample preparation}

Sugarcanes were collected from the sugar cane fields situated around Mysore. Sugar cane juice was extracted from such sugar canes by laboratory crusher $^{8}$; the obtained juice was collected and stored in a separate reagent bottle. The same juice of $5 \mathrm{~mL}$ of that was diluted to $100 \mathrm{~mL}$ with water and filtered to separate any suspended particles ${ }^{25}$.

\section{Detergent sample preparation 5}

$5 \mathrm{~g}$ washing powder of Indian origin was placed in an oven for about half an hour at about $350{ }^{\circ} \mathrm{C}$, the obtained ash was taken in a $150 \mathrm{~mL}$ beaker. It was dissolved in about $50 \mathrm{~mL}$ water and the solution was made acidic by adding dilute sulfuric acid. It was heated on water bath for about $10 \mathrm{~min}$. to expel the hydrogen sulphide, nitrite etc. It was filtered and the filtrate was transferred into a $100 \mathrm{~mL}$ volumetric flask and diluted to the mark with water, later it was used for its phosphate analysis.

\section{Water sample 2,3}

Water sample was collected from Kukkarahalli Lake which is located in Mysore city. Sample was filtered through a cellulose membrane filter, the filtrate containing orthophosphate, condensed phosphate (Pyro, Meta and poly phosphate) and organically bound phosphorous, all of which may be present in soluble form and in suspension. As is well known that only orthophosphate can be determined directly by phosphomolybdate procedures, pyro, tripoly and poly phosphate are completely hydrolyzed to orthophosphate by acidification and heating (30 min.) and it was used for its phosphate analysis.

\section{Results and Discussion}

The developed method is based on the formation of phosphomolybdate ${ }^{11,17,23,25}$ due to the reaction between molybdate and phosphate followed by its reduction with sodium sulphide in aqueous sulfuric acid medium. Under optimized experimental condition, with fixed concentration of molybdate and reducing agent, the colour intensity was found to be proportional to the amount of phosphate present in disodium hydrogen phosphate, sugarcane juices, water and detergent samples. The reaction conditions as well as the various experimental parameters affecting the development and stability of the coloured complex were carefully investigated and optimized for quantitative determination of phosphate in various samples analyzed. The experimental variables such as concentration of ammonium molybdate, concentration of sulfuric acid, concentration of sodium sulphide, order of addition of the reagents and also colour stability of the complex were optimized for the effective determination of phosphate. The stability constant and composition of the system were also determined and values were found to be $1.992 \times 10^{6}$ $\mathrm{L} \mathrm{mol}^{-1}$ and 1:1 with respect to molybdate and phosphate. For a comparison of the results, phosphate present with those various samples was also determined separately following the official method ${ }^{25}$. The results obtained for phosphate both by the proposed and official 
method $^{25}$ are shown in Table 1 and 2 which account for the complimenting nature of the results from both the methods. Therefore, the proposed method could be either a substitute to an official method ${ }^{25}$ or it could also be an independent method for the determination phosphate in the sugarcane juice samples.

Table 1. Determination of phosphate in sugar cane juices.

\begin{tabular}{ccc}
\hline sample & $\begin{array}{c}\text { Phosphate in mg/l by } \\
\text { developed method }\end{array}$ & $\begin{array}{c}\text { Phosphate in mg/l by } \\
\text { official method }\end{array}$ \\
\hline Sugarcane juice-1 & 172 & 170 \\
Sugarcane juice-2 & 195 & 193 \\
Water sample-1 & 52 & 51 \\
Water sample-2 & 15 & 14 \\
\hline
\end{tabular}

Table 2. Determination of phosphate in detergent powders

\begin{tabular}{ccc}
\hline Company & $\begin{array}{c}\text { Phosphate in \% by } \\
\text { developed method }\end{array}$ & $\begin{array}{c}\text { Phosphate in \% by } \\
\text { official method }\end{array}$ \\
\hline Company-A & 19.5 & 20.1 \\
Company-B & 25.2 & 25.1 \\
Company-C & 18.0 & 18.3 \\
\hline
\end{tabular}

\section{Optimization}

\section{Effect of concentration of ammonium molybdate}

First $5.528 \times 10^{-3} \mathrm{M}$ ammonium molybdate solution was prepared ${ }^{29,31}$. Three series, each series having three labeled $10 \mathrm{~mL}$ volumetric flasks were arranged .To each flask of the first series $0.1 \mathrm{~mL}$ of $5.528 \times 10^{-3} \mathrm{M}$ molybdate solution was added. To each flask of the second series $0.3 \mathrm{~mL}$ of $5.528 \times 10^{-3} \mathrm{M}$ molybdate solution was added. To each flask of the third series $0.5 \mathrm{~mL}$ of $5.528 \times 10^{-3} \mathrm{M}$ molybdate solution was added. To the flasks of each series, measured but various volumes $(0.2,0.5,1.0 \mathrm{~mL})$ of phosphate $(30 \mathrm{ppm})$ solution, $1 \mathrm{~mL}$ of $2.0833 \times 10^{-3} \mathrm{M}$ sodium sulphide solutions were added. All the solutions were diluted to the mark with water. The absorbance of the solutions were measured at $715 \mathrm{~nm}$. The first series solutions containing $0.1 \mathrm{~mL}$ of molybdate showed absorbance $0.01,0.02$, and 0.05 for 0.2 , $0.5,1.0 \mathrm{~mL}$ of phosphate. It yielded a straight line, but ran almost parallel to $\mathrm{x}$-axis, indicating low sensitivity. A second series of solutions containing $0.3 \mathrm{~mL}$ of molybdate solutions showed absorbance value $0.02,0.03$ and 0.05 for $0.2,0.5$ and $1.0 \mathrm{~mL}$ of phosphate respectively. This also yielded a straight line but indicated low sensitivity when the absorbance is plotted against concentration of phosphate. A third series of solutions containing $0.5 \mathrm{~mL}$ of ammonium molybdate solutions showed absorbance values of 0.07 , 0.09 , and 0.15 for $0.2,0.5$ and $1.0 \mathrm{~mL}$ of phosphate respectively .The absorbance values were found to increase with concentration of phosphate and the colour of the solutions were stable up to $2 \mathrm{~h}$. Therefore, $0.5 \mathrm{~mL}$ of ammonium molybdate was more preferred than its volume used in the earlier two sets solutions for the determination of phosphate.

\section{Effect of concentration of sulfuric acid}

The effect of concentration of sulfuric acid on absorbance was investigated to achieve high absorbance via taking various volumes (1-3 mL) of $0.25 \mathrm{~N}$ of sulfuric acid , $0.5 \mathrm{~mL}$ of ammonium molybdate, $1 \mathrm{~mL}$ of phosphate $(30 \mathrm{ppm})$ and $1 \mathrm{~mL}$ of $2.0833 \times 10^{3} \mathrm{M}$ sodium sulphide solutions were added to the $10 \mathrm{~mL}$ volumetric flasks. Then, the solutions were 
diluted to the mark with water. Absorbance of each solution was measured at $715 \mathrm{~nm}$. The absorbance of the solutions were $0.02,0.05$ and 0.15 respectively for 1,2 and $3 \mathrm{~mL}$ of $0.25 \mathrm{~N}$ sulfuric acid .The absorbance values indicated that the solution containing $3 \mathrm{~mL}$ of $0.25 \mathrm{~N}$ sulfuric acid appeared to be more sensitive. Therefore, it was used throughout the experiment to determine the phosphate.

\section{Effect of concentration of sodium sulphide}

The concentration influence of reducing agent was studied as above with different volumes $(0.2,0.5,0.7,1.0 \mathrm{~mL})$ of $2.0833 \times 10^{-3} \mathrm{M}$ of sodium sulphide. The absorbance values were found to be $0.05,0.1$ and 0.16 respectively for sodium sulphide. Based on these results; $1.0 \mathrm{~mL}$ of this reagent was selected for the construction of calibration graph.

\section{Effect of order of addition of the reagents}

Different orders of the reagent addition were studied using optimised amounts of reagents following the recommended procedure. The results obtained have shown that the order of reagents addition do not effect absorbance values. But for maintaining the uniformity of the order of reagents addition as mentioned in the recommended procedure was followed throughout course of the determination of phosphate.

\section{Calibration Graph}

Under the optimum condition, a good linear relationship Figure 1 was found to exist between the absorbance of the system and concentration of phosphate 0.3-12.24 ppm with a straight line having slope 0.0336(Cal.) and intercept 0.4667.Molarabsotptivity, correlation coefficient, and Sandell's sensitivity values were calculated and were found to be $6.103 \times 10^{3} \mathrm{~mol}^{-1} \mathrm{~cm}^{-1} 0.999$ and $0.0156 \mu \mathrm{g} \mathrm{cm}^{-2}$ respectively. The precision and accuracy of the method were studied by analyzing a series of solution containing known amount of phosphate $(0.3,3.0$ and $10.7 \mathrm{ppm})$ by using recommended volumes and concentration of the reagents. The precision of the method as expressed by relative standard deviation was less than $3.7 \%$ whereas the accuracy expressed by the calculated relative error was $3.4 \%$.

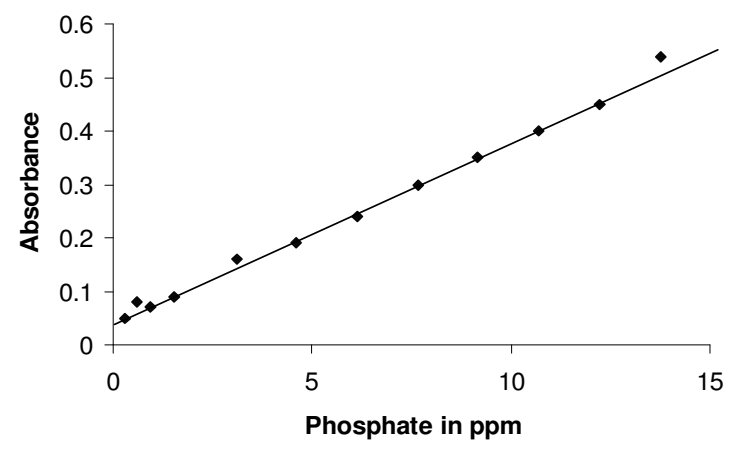

Figure 1. Calibration graph for the determination phosphate under optimized experimental condition.

\section{Effect of foreign ions}

The effect of foreign ions were examined by using $3 \mathrm{ppm}$ of phosphate and the results obtained are shown in Table 3. Most of the cations and anions commonly found in sugar cane juice ${ }^{7,8}$ do not interfere but iron; copper and zirconium interfere at 20, 12, and $11 \mathrm{ppm}$ respectively. 
Table 3. Effect of foreign ions on the determination of phosphate.

\begin{tabular}{ccc}
\hline Ion & Salt added & Tolerance limit in ppm \\
\hline $\mathrm{Na}^{+}$ & $\mathrm{NaCl}$ & 120 \\
$\mathrm{~K}^{+}$ & $\mathrm{KCl}$ & 209 \\
$\mathrm{Mg}^{2+}$ & $\mathrm{MgSO}_{4}$ & 400 \\
$\mathrm{Fe}^{3+}$ & $\mathrm{Fe}\left(\mathrm{NH}_{4}\right)_{2}\left(\mathrm{SO}_{4}\right)_{2}$ & 20 \\
$\mathrm{Ni}^{2+}$ & $\mathrm{NiSO}_{4}$ & 20 \\
$\mathrm{Cu}^{2+}$ & $\mathrm{CuSO}_{4}$ & 12 \\
$\mathrm{Cd}^{2+}$ & $\mathrm{CdSO}_{4}$ & 192 \\
$\mathrm{Zr}^{4+}$ & $\mathrm{ZrOCl}_{2}$ & 11 \\
\hline
\end{tabular}

\section{Conclusions}

The proposed method is working on simple and straight forward principles of the reduction of phosphomolybdate ${ }^{11,17,23,24}$ by sodium sulphide leading to molybdenum blue which was monitored at, $\lambda \max 715 \mathrm{~nm}$ The developed method found to be having the following advantages over the reported methods. ${ }^{14-17,23,25,27,32}$. (i) It is more sensitive when compared to the reported method ${ }^{17}$. (ii) The preparation of reducing agent in this method is very simple when compared to that in the official method ${ }^{25}$. (iii) It neither involves extraction ${ }^{19}$ nor sophisticated instruments like HPLC, ${ }^{16}$ flow injection spectrophotometer ${ }^{15}$ and atomic spectroscopy $^{14}$, nor requires strict control of $\mathrm{pH}^{23,27,32}$ or temperature or heat treatment ${ }^{32}$.

As the method is observed to be working satisfactorily for the determination of phosphate in various samples giving the results which are not only comparable with the results of phosphate determined separately from an official method ${ }^{25}$ and also reproducible as revealed by the values of statistical parameters like standard deviation, $3.7 \%$ and relative error, $3.4 \%$. Therefore, the method could be employed for the determination of phosphate as an independent or a complimentary one to the official method ${ }^{25}$.

\section{Acknowledgement}

One of the authors Mahadevaiah is grateful to the University of Mysore, Mysore for awarding Teacher fellowship.

\section{References}

1. Cairl McCarty, Perryl McCarty and Gene F Parkin, Chemistry for environmental engineering and Science $5^{\text {th }}$ Ed., Tata McGraw- Hill Publiushing Company Ltd, 2003677.

2. Mohammed Yaqoob, Abdul Nabi and Paul J Worfold, Anal.Chim.Acta, 2004, 510, 213.

3. Soji motomizu, ToshiakiWakimoto and Kyojitoei, Talanta, 1982, 138, 329.

4. Torres F M, Estela J M, Miro M, Cladera A and Cerda V, Anal Chim Act, 2004, 510, 61.

5. Kamath D K, Savanth V C, Suryanarayana D N, Talanta, 1995, 42(3), 365.

6. Bridger G L, Boylam D R and Markey J W, Anal.Chem, 1953, 25(2), 336.

7. Honig P, Principles of cane sugar Technology, Elsevier publishing company New York 1953, 2, 340.

8. Mathur R B L, Hand book of Cane Sugar Technology, $2^{\text {nd }}$ Ed, Oxford and IBH Publishing Co, Pvt, Ltd, New Delhi, 1995, 621.

9. Paschkes B, and Berman B, Anal. chim. Acta, 1961, 24, 5.

10. Susic S K, Njengovan V N and Solaja B, Z. Anal.Chem, 1961, 183, 412.

11. Mamadal S and Kundu D. J.Indian Chem.Soc. 2005, 82, 1030. 
12. Williams K E and Haswell S J, Analyst, 1993, 118, 245.

13. Krishanamurthy N and Suryanarayana A V, Z. Anal.Chem, 1982, 312, 548.

14. Christian G D and Feldman F J, Anal .Chem. Acta, 1968, 40, 173.

15. Shoji Motomizu and Mitsuko Oshima, Analyst, 1987, 112, 295.

16. Hans Erik Botker, Hans Henrik Kimose, Per Helligs $\varnothing$ and Torsten Toftegaard Nielsen, Journal of Molecular and Cellular Cardiology, 1994, 26, (1), 41.

17. Johanna M.Smeller, Analyst, 1995, 120, 207.

18. Hayashi K, .Dazuka T and Ueno K, Talanta, 1960, 4, 244.

19. Borissova R and Mitropolitska E, Talanta, 1979, 26, 543.

20. Vincent P Gutschik, Talanta, 1985, 32, 93.

21. Shoji motomizu, Wakimoto T and Toei K, Talanta, 1984, 31, 235.

22. Motomizu S, and Misuko Oshima, Analyst, 1987,112, 295.

23. Yathirajam V, and Dhamija S, Talanta, 1977, 24, 497.

24. John H Payne "Sugar cane factory analytical control" Revised edition, Elsevier publishing company, New York, 1968, 62.

25. Verma N C, "System of technical control for cane sugar factories in India", Published by STAI , 1988, 33.

26. Theodore G Towns, Anl.Chem, 1986, 58, 223.

27. Burton J D, Water Res., 1971, 7, 294.

28. Nidal A, Zater, Maher A, Abu-Eid and Abdullah F Eid, Talanta, 1999, 50(4), 819.

29. Mansur S Abdul Galil and G Nagendrappa, J. Saudi Chem Soc, 2006, 10, 225.

30. AI Vogel's A Text Book of quantitative chemical analysis $5^{\text {th }}$ Ed Longmans London 1991.

31. Mahadevaiah, Mansour S Abdul Galil and G Nagendrappa, J. Anal. Chem. (Russia) 2007. (In press)

32. Ueda T, Hojo M and Shimizu K, Analytical Sciences, 2001, 17, 1431. 


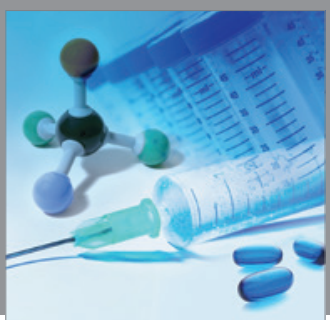

International Journal of

Medicinal Chemistry

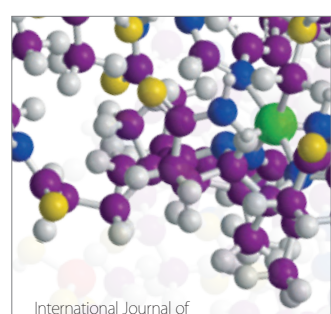

Carbohydrate Chemistry

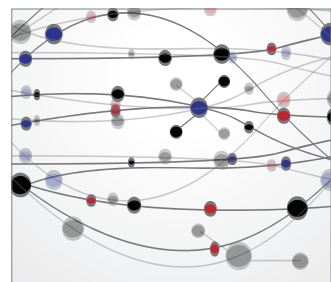

The Scientific World Journal
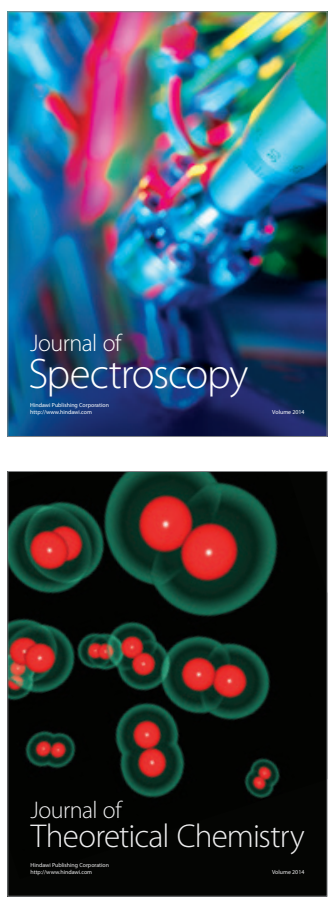
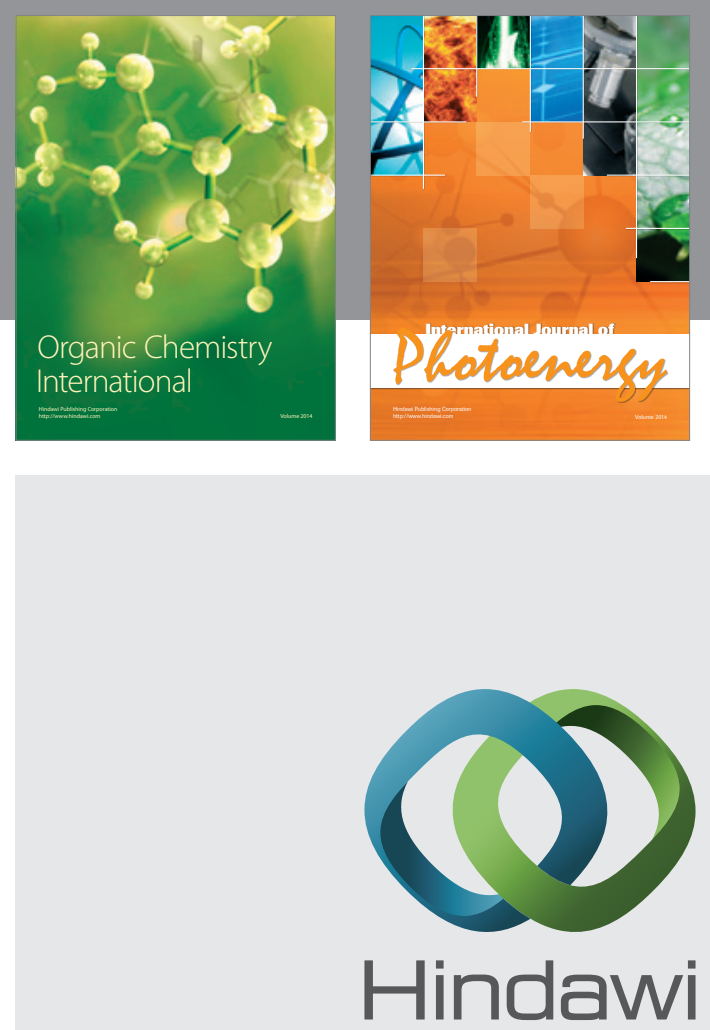

Submit your manuscripts at

http://www.hindawi.com
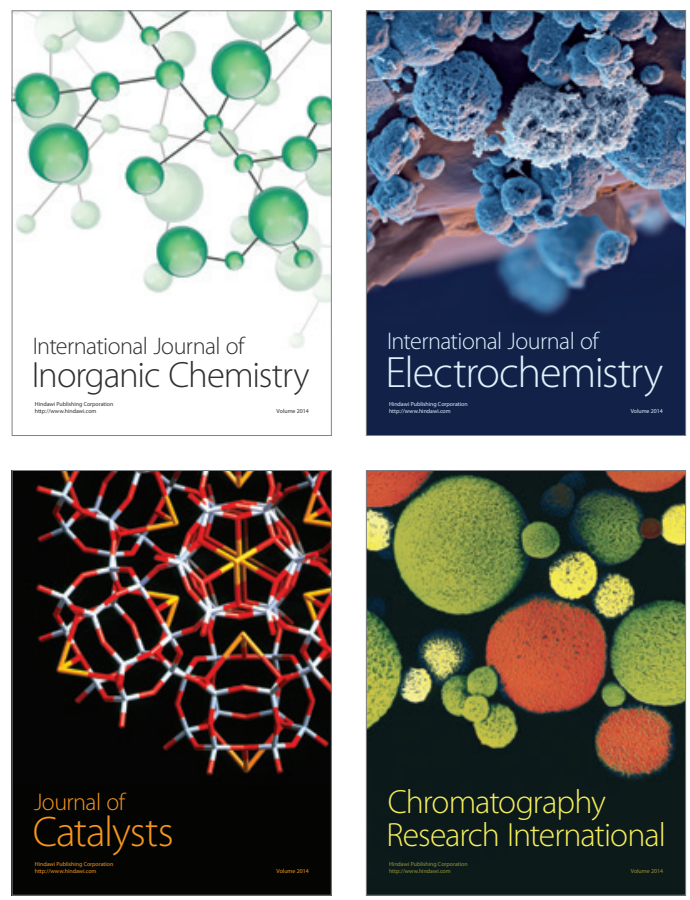
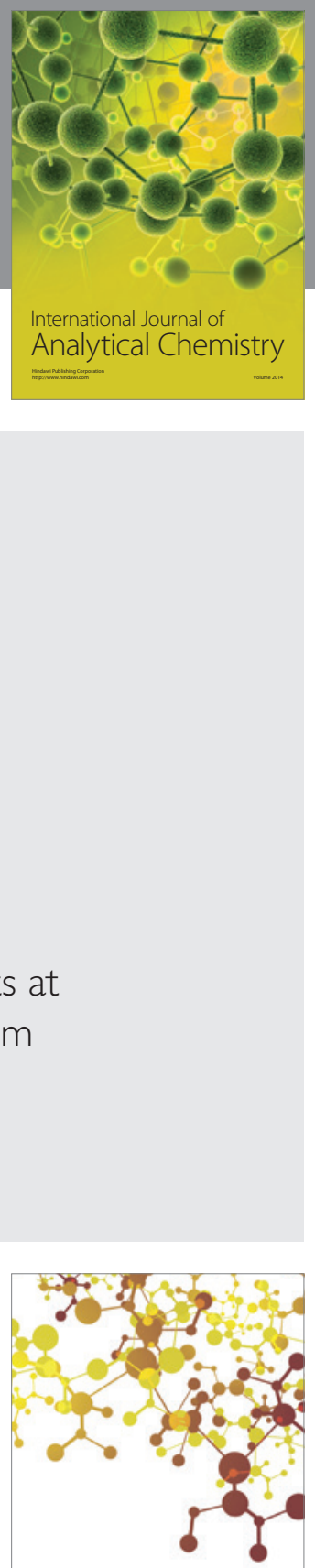

Journal of

Applied Chemistry
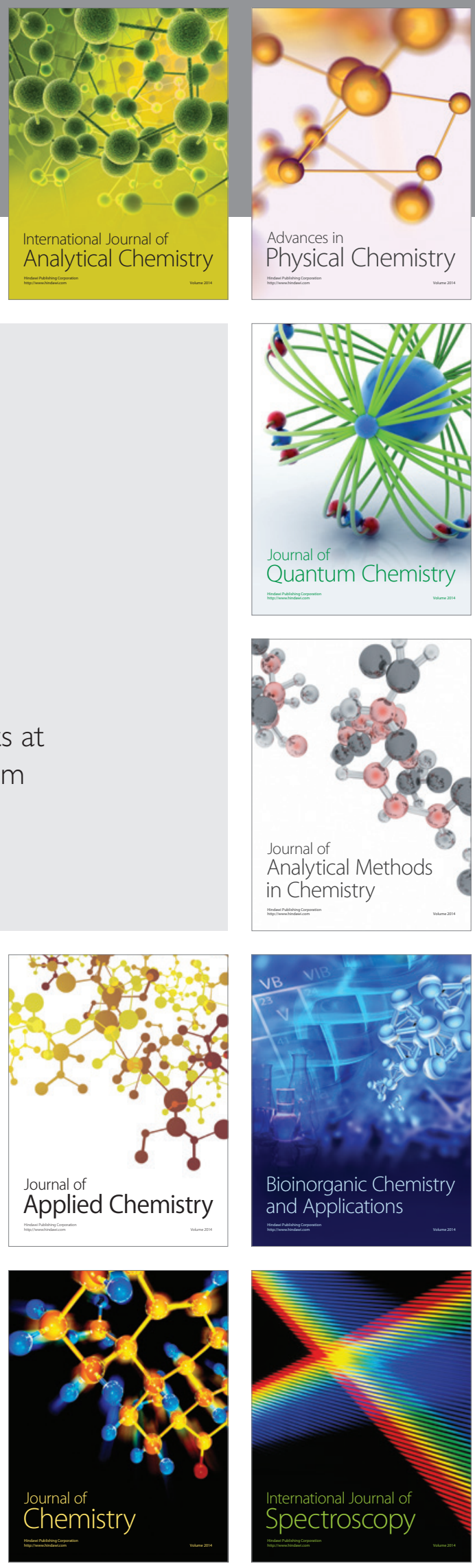